\title{
A literature review of issues affecting PrEP Education and Implementation in racism mistrust in black communities (HIV/AIDS)
}

\author{
Cazeau $\mathbf{P}^{1 *}$, Jackson $\mathrm{R}^{2}$, Theodore $\mathrm{L}^{3}$ and Balatien $\mathrm{B}^{3}$ \\ ${ }^{1}$ Public Health Diplomat, Committee Member at Mayor Thomas A Masters Citizens Response Team, USA \\ ${ }^{2}$ Chair HIV Program, Northwood University, USA \\ ${ }^{3}$ Chief medical in HACI, University of Cincinati, USA
}

\begin{abstract}
Background: Racism in black communities has complicated diagnosis and treatment of the HIV/AIDS epidemic. Individuals most affected by HIV are also most disadvantaged in terms of race and economic status. Sixty percent of all new HIV infections take place among young black MSM between the ages 13 to 29 , which explains why AIDS has been cast as a social and not bio-medical problem. Most of them will live in disbelief that they could be at risk for HIV, and so are reluctant to try new preventative treatments such as PrEP.

Methodology: This study is a literature review to explore how pre-exposure prophylaxix is related to health, behavioral, stigma, racism, and psycho behavioral. A descriptive statistics were generated for demographics, sexual behaviors, concerns and interests about PrEP. Thirty-three participants were recruited from eastern and western counties of HIV-uninfected men who report having sex with men (MSM) through their level of agreement on statements listing concerns about the impact of PrEP use on health, behavior, stigma, and interest in psycho-behavioral support services to PrEP.Bivariate and multivariable logistic regression procedures examined a willingness to use the oral PrEP.

Results: Mean age of participants was 13-29 YMSM. Participants were enrolled in the PrEP Program compared with MSM and IDU (inject drug) of PrEP use on health, behavior, stigma, and interest in psycho-behavioral support services to PrEP. We found 5 percent has more than half reporting more than two partners. Whereas 6 percent of IDU reported inconsistent condom used; 33 percent had previously heard of PrEP, whereas $6 \%$ reported to use oral PrEP if available after being educated about its potential. In multivariable analysis controlling for age and race/ethnicity demographic significant to use oral PrEP included the following: less education [odds ratio $(\mathrm{OR})=7.7 ; \mathrm{P}=0.04$ ], moderate income $(\mathrm{OR}=13.0 ; \mathrm{P}=0.04)$, no perceived side effects from taking $\mathrm{PrEP}(\mathrm{OR}=3.5 ; \mathrm{P}=0.001)$, and not having to pay for $\operatorname{PrEP}(\mathrm{OR}=4.2 ; \mathrm{P}=0.05)$.

Conclusion: Black MSM who were HIV negative and who took PrEP while involving in relationship with HIV positive men remained HIV negative. Knowledge of PrEP and its implementation must overcome the same level of mistrust in the black community in order to become recognized as an important factor in reducing the AIDS virus.
\end{abstract}

\section{Introduction}

World Health Organization (WHO), 1948 stated health is more than the absence of diseases, as a negative definition of health will never entail the positive aspects of possessing health. WHO has stated that health necessarily includes social, psychological and physical wellbeing. This means that any measurement of health needs to include non-epidemiologic factors that points to the positive components in the construction of health. Engel (1960) employed the "Biopsychosocial model" to clarify the different elements that must be understood, evaluated, and treated when faced with caring for unhealthy patients. This model for Engel also meant that health must include social, biological, psychology and other determinants.

Caldwell (1993) noted how behavioral and lifestyle practices are key determinants in health, and the lack thereof leading to mortality is not new. Despite this, Bharat (2002) has pointed out an acknowledged truism known throughout the world that those individuals most affected by HIV are also the most disadvantaged in terms of race, economic status, age, sexual orientation or gender [1-3]. He documented how the nearly two decades-old global history of the HIV epidemic undergirds once again the well-established interplay of disease, stigma and identities gone bad based on race, ethnicity, and sexuality. The strong connections established early between HIV/AIDS and gay men plus other risk groups appear to have blinded social researchers and others to indicators of racial, class and gender relations that cast AIDS as a social and not a bio-medical problem. Williams (1997) relates how race is pertinent to questions of public health, care and treatment issues, and how it's crucial to first examine the phenomena of stigma and discrimination and secondly how its related to illness and disease. Goffman (1963) defined stigma as a discrediting characteristic which

Correspondence to: Cazeau P, Public Health Diplomat, Committee Member at Mayor Thomas A Masters Citizens Response Team, USA

Key words: PrEP, Stigma, Racism, HIV/AIDS

Received: January 16, 2017; Accepted: February 11, 2017; Published: February 14,2017 
in the eyes of society reduces the person who has it [4]. Goffman said the stigmatized individual was seen to be a person with "an undesirable difference" and maintained stigmas are constructed by society using perceived difference or deviance and carried through socially approved roles and sanctions.

AIDS appeared to have come quickly on the scene from nowhere, and as terrifying as it seemed, health officials and the media gave assurances to the public that its cause came from the consequences of gay promiscuity and not pathogens. While African-Americans individually disbelieved, they were at risk for HIV infection, they knew perfectly well its threat to their communities [5-9]. A study revealed that although Blacks account for only 14 percent of the total U.S. population, they unfortunately represent nearly one-half of the estimated 50,000 new cases of HIV that occur every year and secondly about 500,000 of the almost 1.2 million people living with HIV/AIDS (HRSA,2012) (Table 1 and 2).

Another study uncovered how black MSM have been the most heavily impacted by HIV/AIDS in their community. Despite only 4 percent of males age 13 and older in the United States are MSM, they accounted for 61 percent of all new HIV infections in 2009 [10-17]. The African-American MSM constitute a majority of these cases, with sixty percent of all new HIV infections taking place among young black MSM between the ages 13 to 29.

The CDC Young Men's Survey (1994-2000) showed how black MSM were diagnosed with HIV at rates five times those of their white counterparts. This study revealed that 82 percent were not aware they were infected until a later time and most denied they were at risk for HIV in their lifetime $[18,19]$. The study revealed how homophobia plays a determinant in preventing black MSM from understanding their risk for HIV, or avoiding HIV prevention and testing plus treatment and care services. African-American MSM will continue to have relationships with older black MSM for access to housing, food and other resources in order to survive. Although these relationships are often caring, they have helped perpetuate HIV across several

Table 1. Source: CDC. CDC fact sheet: Estimates of new HIV infections in the United States,

2006-2009. Available at www.cdc.gov/nchhstp/newsroom/docs/HIV-Infections-2006-2009.pdf. Accessed December 15, 2011.

\begin{tabular}{|c|c|c|c|}
\hline Gender & White & Hispanic & Black \\
\hline Male & 15.9 & 39.9 & 103.9 \\
\hline Female & 2.6 & 11.8 & 1,189 \\
\hline
\end{tabular}

Table 2. Palm Beach Living HIV/AIDS Cases Currently Living in Palm Beach County.

\begin{tabular}{|c|c|c|}
\hline City & $\begin{array}{c}\text { Eastern/ Western } \\
\text { Living HIV/AIDS Cases }\end{array}$ & $\begin{array}{c}\text { Percent of } \\
\text { Living Cases }\end{array}$ \\
\hline Belle Glade** & 495 & $6 \%$ \\
\hline Boca Raton & 456 & $6 \%$ \\
\hline Boynton Beach & 853 & $10 \%$ \\
\hline Delray Beach & 952 & $12 \%$ \\
\hline Greenacres & 134 & $2 \%$ \\
\hline Jupiter & 114 & $1 \%$ \\
\hline Lake Worth & 1063 & $13 \%$ \\
\hline Lantana & 144 & $2 \%$ \\
\hline Pahokee** & 91 & $1 \%$ \\
\hline Palm Beach Gardens & 112 & $1 \%$ \\
\hline Riviera Beach & 484 & $6 \%$ \\
\hline West Palm Beach & 2676 & $7 \%$ \\
\hline All Other Cities* & 609 & $\mathbf{1 0 0} \%$ \\
\hline Total & $\mathbf{8 1 8 3}$ & \\
\hline
\end{tabular}

generations of black MSM.

Researchers are showing interest into an effective HIV prevention using a pill, with dozens of studies having queried potential target users on their willingness to undergo a daily dose of antiretroviral drugs in order to protect themselves from HIV [20-22]. Studies have reported on the willingness to use PrEP with interest factors in association with a daily oral prevention pill and pinpoint user's concerns with taking a daily drug as prevention intervention. Another study reported on the acceptability of daily oral pre-exposure prophylaxis (PrEP) involving men who have sex with men (MSM) and recorded a wide range of acceptability from a low of 28 percent to a high of 96 percent. Meyers et al., (2014) stated these studies aimed to identify demographic and behavioral factors, particularly sexual risk factors associated with a higher interest in daily oral PrEP [23-24].

\section{Methodology}

Thirty-six literature reviews were identified to investigate how preexposure prophylaxix is related to health, behavioral, stigma, racism, and psycho behavioral. A study by Meyers et al., (2014) set out to extend these research questions to explore the willingness to use longacting injectable (LAI) formulations of PrEp. All participants were evaluated for LAI-PrEP using information from trained interviewers on the possible side effects of oral and LAI-PrEP. Participants were asked to recall the number of partners in the last three months and frequency of condom use [25-27]. Descriptive statistics of PrEP were employed for purposes of demographics, sexual behavior, concerns and interest (Figure 1).

Haire (2015) stated that PrEP will work provided it is taken, making adherence a significant challenge of effective PrEP implementation together with issues of access and uptake [28-31]. A PrEP-related stigma has emerged among research participants, as reported by trial participants from a variety of trial sites. Liu et al., found that experiencing a stigma was the most commonly reported social harm stemming from study participants, with 15 of 20 listed social harms connected to stigma. A qualitative study of MSM who participated in the iPrEX study in Chiang Mai, Thailand Tang-munkongvorakul et al., found that stigma was a challenge to medication adherence, and noted several different kinds of stigma experienced by study participants [32-35]. (Haire, 2005). Smith et al., noted how the anticipated negative reaction of peers, friends, and family members was seen as a factor mitigating against PrEP uptake among African-Americans between ages 18-24 [36].

\section{Measures}

Researchers have cautioned that although PrEP may offer some prevention to MSM who find condom use difficult, it could also promote lack of condom use [37]. Although researchers have found no evidence of condom neglect in clinical trials, the absence of evidence may be attributable to the wide-ranging psychosocial services offered as part of the trials (e.g., access to behavioral counseling, free condoms, treatment for sexually transmitted infections (STI), regular HIV testing, and frequent medical evaluation) as well as a limited number of recruited youth. (Bauermeister et al., 2013). A recent study by Mustanski and colleagues found PrEP intentions were associated with fewer acts of unprotected anal sex [38]. It therefore remains unclear whether YMSM's health promotion and risk practices may influence their PrEP intentions, or whether these findings can be generalized to other geographic areas. 
Figure 1. Percent of Living HIV/AIDS by Eastern/Western County $n=8183$.

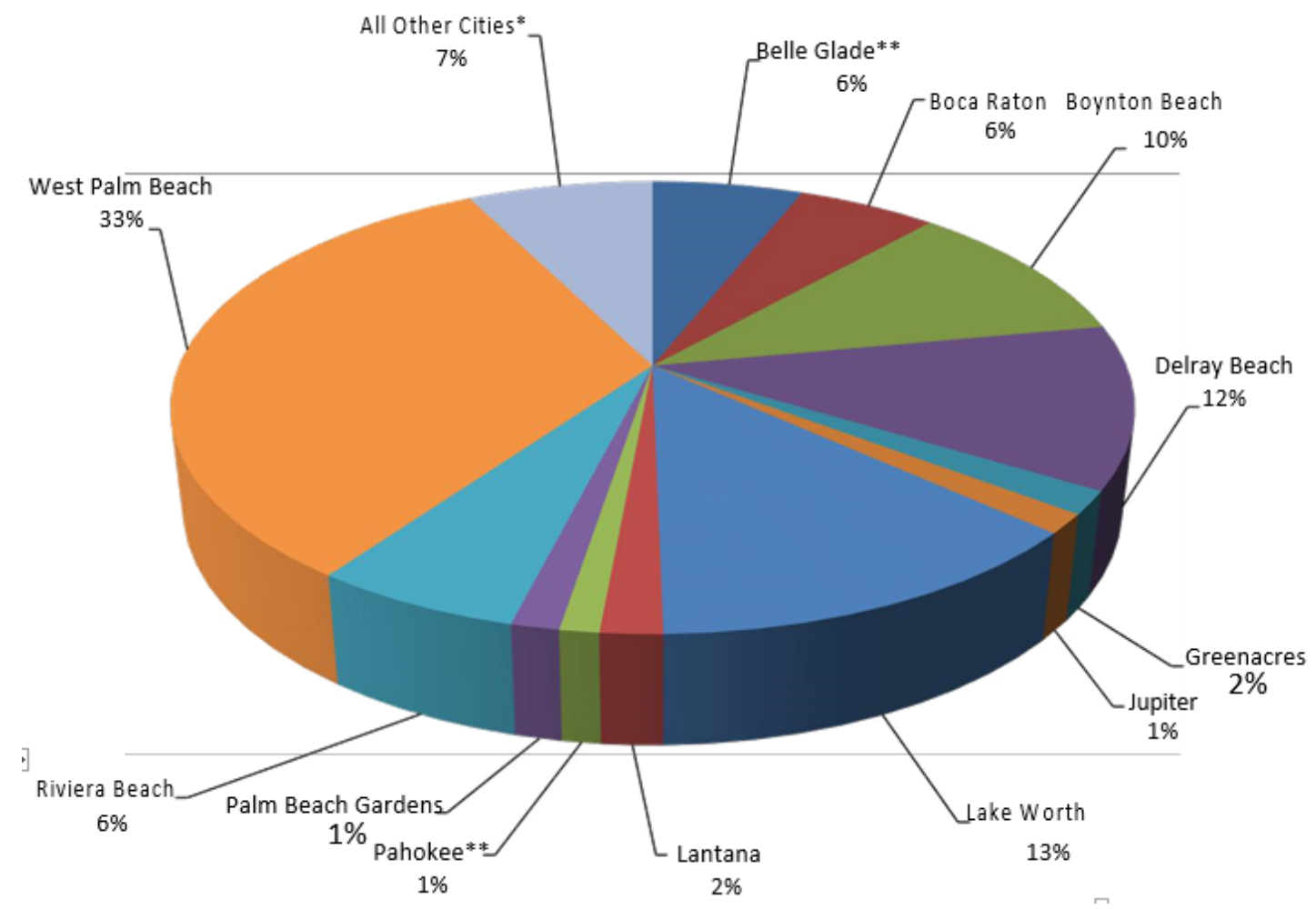

Data Source: FL DOH, Bureau of Communicable Diseases, HIV/AIDS and Hepatitis Section, data as of October 31, 2016.

*Other cities are combination of the cities that had less than 100 cases per city.

**Western Palm Beach includes Belle Glade, Pahokee, South Bay, Canal Point, Lake Harbor and Bryant.

***Eastern Palm Beach includes all cities not listed as Western Palm Beach.

\section{Data analysis}

For this study, thirty-three participants were recruited from eastern and western counties of Florida by zip code that were enrolled in the PrEP Program compared with MSM and IDU (inject drug) [39]. Participants were asked to state their level of agreement on statements listing concerns about the impact of PrEP use on health, behavior, stigma, and interest in psycho-behavioral support services to PrEP [40]. A second set of recruits consisted of 1449 participants of MSM living with HIV and sexually active with HIV negative taking PrEP. Descriptive statistics were generated for demographics, sexual behaviors, concerns and interests about PrEP. Chi-square and when suitable a Fisher's Exact Test were employed to test independent associations among outcomes, plus demographic and behavioral predictors. We modeled each of the two outcomes with bivariate analysis using demographic and behavioral factors as well as previous reported concerns connected to a willingness to use oral PrEP. A small sample size involving the multivariable model included factors that were significant at $\mathrm{p}<0.10$ level in the bivariate model, therefore there is no significant difference.

\section{Results}

There was a wide distribution of the number of male sexual partners between January 2016- October 2016 in eastern and western counties of Florida with more than half reporting more than two partners $(5 \% n=179)$ [41]. We found $6 \%(n=436)$ of IDU reported inconsistent condom use in eastern Palm Beach living with HIV while $33 \%(n=2507)$ MSM reported hardly ever or never using condoms
[42]. We found $6 \%(n=40)$ of IDU reported inconsistent condom use in western Palm Beach living with HIV, while $0 \%(n=1)$ MSM reported using condoms and participated in taking oral PrEP. We found 33\% had previously heard about PrEP, whereas 6\% reported to use oral PrEP if available. A Multivariable analysis used to control for age, race, demographic, social behavior to use oral PrEP. significant to use oral PrEP included the following: less education [odds ratio $(\mathrm{OR})=7.7 ; \mathrm{P}=$ 0.04 ], moderate income $(\mathrm{OR}=13.0 ; \mathrm{P}=0.04)$, no perceived side effects from taking $\operatorname{PrEP}(\mathrm{OR}=3.5 ; \mathrm{P}=0.001)$, and not having to pay for $\operatorname{PrEP}$ $(\mathrm{OR}=4.2 ; \mathrm{P}=0.05)[43]$.

\section{Conclusion}

Since the beginning of the HIV epidemic, those most effected have also been the most disadvantaged in terms of race, economic status, and most importantly sexual orientation. But HIV has also been plagued by a stigma ranging from researchers to society with the net result ending with discrimination. This stigma has prevented black men from not only undergoing testing but also seeking treatment including a daily oral pre-exposure proplylaxis (PrEP). Black MSM who were HIV negative and who took PrEP while involving in relationship with HIV positive men remained HIV negative. Knowledge of PrEP and its implementation must overcome the same level of mistrust in the black community in order to become recognized as an important factor in reducing the AIDS virus.

\section{References}

1. Aissata, Diop D (2001) Panel discussion at the CSW 45th session, 6-16, March 2001, Geneva. 
2. Bharat S (1999) AIDS related discrimination, stigmatization and denial in India. Geneva: UNAIDS

3. Bharat SAggleton P, Tyrer P (2001) India: HIV and AIDS-related Discrimination, Stigmatisation and Denial. (UNAIDS Best Practice Collection - Key Material). UNAIDS: Geneva.

4. Bharat S, Aggleton PJ (1999) Facing the Challenge: Household responses to AIDS in India. AIDS Care 11: 31-44.

5. Bollini S (1995) No real progress towards equity: Health of migrants and ethnic minorities on the eve of the year 2000. Social Science and Medicine 41: 819-828.

6. Bungener C, Gonod MN, Jouvent R (2000) African and European HIV-positive women: Psychological and psychosocial differences. AIDS Care 12: 541-548.

7. Canada Bureau of HIV/AIDS, STD and TB (2001) AIDS/HIV ethnicity in Canada (HIV Epi Update May 2001).

8. Centers for Disease Control and Prevention - CDC (2000) Young people at risk: HIV/ AIDS among America's youth. Atlanta, Georgia.

9. Common Wealth of Australia (1997) The national indigenous Australian's Health Strategy 1996/7 - 1998/9

10. Cowater International Inc (1996) Communidades de Ancestria Africana en Costa Rica, Honduras, Nicarague, Argentina, Colombia, Ecaudor, Peru, Uruguay, Venezuela. Washington, DC, USA

11. Farmer P, Kim JY (1991) Anthropology, accountability and the prevention of AIDS Journal of Sex Research 28: 203-221.

12. FOASE (2000) Housing, services, child health all lag far behind. Latin News, 12

13. Foucault M (1977) Discipline and Punish. New York: Pantheon.

14. Foucault M (1978) The History of Sexuality, Volume I: An Introduction. New York: Random House.

15. Goffman E (1963) Stigma: Notes on the Management of a Spoiled Identity. New York: Simon and Schuster.

16. Gostin LO, Lazzarini Z (1997) Human Rights and Public Health in the AIDS Pandemic. New York: Oxford University Press.

17. Herek G (2002) Thinking about AIDS and Stigma: A Psychologist's Perspective. Journal of LawMedicine \& Ethics 30: 1-14.

18. Herek GM, Capitanio JP (1993) Public reactions to AIDS in the United States, a Second decade of stigma. American Journal of Public Health 83: 574-577.

19. Herek G (1990) Illness, stigma and AIDS. In Psychological Aspects of Serious Illness: Chronic Conditions, Fatal Diseases and Clinical Care: 107-150.

20. Health Canada (1999) HIV and AIDS in Canada. Surveillance report to December 31, 1998. Ottawa.

21. Human Rights Watch (1996) Sheltered lives: Sexual violence during the Rawandon genocide and its aftermath.

22. Kaleeba N, Kalibala S, Kaseje M, Ssebbanja P, Anderson S, Praag VE, et al. (1997) Participatory evaluation of counseling medical and social services of The AIDS Support Organisation (TASO) in Uganda, AIDS Care. Indian J Palliat Care 9: 13-26.
23. Lie GT, Biswalo PM (1996) HIV-positive patient's choice of a significant other to be informed about the HIV-test result, findings from an HIV/AIDS counseling programme in the regional hospitals of Arusha and Kilimanjaro, Tanzania. AIDS Care 8: 285-296.

24. Liskin L, Blackburn R, Maier J (1986) AIDS: A public health crisis. Population Reports, Series L, No.6. Baltimore: JHU.

25. Low N, Paine K, Chisholm D, Obonyo N, Strorkey M, Youssef S, et al. (1996) African communities in London: Demography and the epidemiology and economics of HIV infections. London: Inner-London HIV Commissioners.

26. Malcolm A, Aggleton P, Bronfman M, Galvao J, Mane P, Verrall J (1998). HIV-related stigmatization and discrimination: Its forms and contexts. Critical Public Health 8 : 347-370.

27. Marshall G (1998) Oxford Dictionary of Sociology. Oxford and New York: Oxford University Press.

28. Nickens HW (1995) Race/ethnicity as a factor in health and health care. Health services research Part II: 151-177.

29. Paget DZ (1998) HIV/AIDS and the legislature: An international comparison. AIDS Care 10: 565-573.

30. Parker R, Aggleton PJ (2002) HIV and AIDS related stigma and discrimination: A conceptual framework and implications for action. ABIA \& TCRU.

31. PAHO, WHO/UNAIDS (2001) HIV and AIDS in the Americas: An epidemic with many faces. Geneva.

32. Postell W (2002) Health of Slaves on Southern Plantations. Baton Rouge: Louisiana State University Press, 1951.

33. Randall VR (2001) Race Relations - Result - 2001. The University of Dayton.

34. Sabatier R (1988) Blaming Others. London: The Panos Institute.

35. Scambler G, Hopkins A (1986) Being epileptic, coming to terms with stigma. Sociology of Health and Illness 8: 26-43.

36. Solon O, Barrazo AO (1993) Overseas contract workers and economic consequences of the HIV and AIDS in the Philippines. In Bloom D.E. \& Lyons, JV, (eds). Economic Implications of AIDS in South East Asia. New Delhi, UNDP.

37. Stiles CW (2002) Hookwork in the Relation to the American Negro. Southern Medical Journal 2: 1125-26.

38. Topouzis D, Guerny DJ (1999) Sustainable agricultural / rural development and vulnerability to the AIDS epidemic. Geneva: UNAIDS \& FAO.

39. UNAIDS/WHO (2001) Fighting HIV related intolerance: Exposing the links between racism, stigma and discrimination.

40. UNAIDS (1999) Gender and HIV/AIDS: Taking stock of research and programmes Geneva: UNAIDS.

41. UNAIDS (2000) A human rights approach to AIDS prevention at work: The Southern African Development Community's code on HIV/AIDS and employment. Geneva.

42. UNAIDS (2000) Report on the global HIV/AIDS epidemic. Geneva.

43. UNAIDS/WHO (1999) AIDS epidemic update. Geneva.

Copyright: ( 2017 Cazeau P. This is an open-access article distributed under the terms of the Creative Commons Attribution License, which permits unrestricted use, distribution, and reproduction in any medium, provided the original author and source are credited. 